\title{
WORKSHOP
}

\section{A MODEL TO EVALUATE THE REBUILDING COSTS OF DWELLINGS}

\author{
By Freddy Corlier, Jean-François Ingenbleek \\ AND Jean Lemaire
}

Université Libre de Bruxelles

\begin{abstract}
Under-insurance is one of the scourges of homeowner insurance: when it is established after a claim that the rebuilding cost of a dwelling has been underestimated by the policyholder, the proportional rule applies in the sense that the indemnity is reduced in proportion of the under-insurance. To avoid this dramatic problem, prejudicial to all parties concerned, a Belgian company has in 1983 marketed a model to evaluate rebuilding costs: if the policyholder fills in correctly a two-page form, the company forgoes the application of the proportional rule.

The construction of this model is explained; then, it is shown how a statistical study sponsored by the Professional Union of Insurance Companies allowed the model to improve.
\end{abstract}

\section{INTRODUCTION}

In Belgium as in most countries, fire insurance is not compulsory and companies are free to set up their own rates and conditions; it is up to the owner or the tenant of a dwelling to decide whether or not he takes out insurance against fire, water damage, natural disasters, and so on. It is also up to the policyholder to determine the sum insured, which is the maximum amount the company will pay in respect of loss of or damage to the building; therefore the sum insured for the owner should amount to the total cost of rebuilding the home, including architects' and surveyors' fees, taxes, ...; as for the tenant, Belgian law stipulates that the sum insured should equal the "real" value of the dwelling, i.e., the rebuilding cost less depreciation and wear and tear.

In the event that the value of the dwelling has been under-estimated by the policyholder, the so-called "under-insurance" clause applies: if the building is totally destroyed by fire, the insured only collects the sum insured, which is insufficient to rebuild the dwelling; in case of partial loss, the indemnity is reduced in proportion of the under-insurance (proportional rule). For instance, assume a policyholder has insured his apartment for a sum of 2 million Belgian Francs. If a claim of 300000 Francs is made, and if the expert assesses the rebuilding value at 3 million, the claimant will only collect two thirds of the claim amount, i.e., 200000 Francs.

An examination of the claim costs of a large Belgian company has shown that under-insurance is a dramatic problem: more than half of the homes are underinsured by more than $10 \%$ (the clause is usually not applied when under-insurance does not exceed $10 \%$ ); moreover, when the proportional rule is applied, the claim amounts are on the average reduced by $40 \%$. So we can infer that the 
average policyholder is under-insured by at least $20 \%$ (and that the premium income of the companies is at least $20 \%$ below the correct level, since in Belgium the premium is proportional to the sum insured).

Two major reasons could be put forward to attempt to explain this phenomenon:

1. the confusion between the selling price of a dwelling and its rebuilding cost.

Due to the current depression of the real estate market and other reasons such as the high interest rates on mortgage loans, the unattractedness of some districts, the fact that some building materials have become obsolete, . ., the buying price of a house is usually substantially lower than its rebuilding cost, even if the construction date is fairly recent. It is very difficult for a broker to entice his client to insure his house for 5 million when he just bought it for 3 million;

2. the tendency of brokers to reduce premiums by decreasing the sums insured.

It has been observed that insurance intermediaries, when they feel the client is reluctant to sign because he cannot afford the premium, have a natural tendency to decrease the sum insured, although it would be much more rational to suggest a policy with a deductible. A consequence is that most policyholders are fully compensated when there is a cigarette hole in their slippers or a short-circuit in their electric coffee-pots, but are severely penalized when their houses are burnt down.

It is thus of utmost importance for a policyholder to estimate correctly the value of his house (as in most cases the sum insured is linked to the construction prices index, he will then only have to adjust this sum when he carries out major alterations to his home). Yet the methods available to him are usually very imprecise or inapplicable. Three methods can be considered:

1. the assessment by a real estate expert or an architect.

This method is the only one capable of providing a reliable estimate of the correct sum to insure; however it is hardly ever used for private dwellings, since the cost of the assessment usually exceeds an annual premium: policyholders fail to understand why they should pay a double premium during the first policy year and insurance companies are not willing to forfeit the first premium on a policy that can be cancelled annually.

2. The updating of the initial construction cost.

In order to apply this method, it is necessary to know the exact cost of the building and of all subsequent modifications. It is compulsory to check whether labour and material were charged at a "normal" price, since in difficult times many contractors tend to work at cost prices, in order to make full use of manpower and equipment. It is also necessary to take into account the work carried out personally by the owner and his relatives. The scope of the method is very limited, since most of these elements are usually unknown if the policyholder is not the first owner.

3. The "comparison" method.

This method, suggested by many insurers, is based on the empirical fact that the values of two "similar" buildings are generally in proportion to their surfaces (or volumes). The policyholder has to: 
(a) Calculate the total floor area (or the total volume).

(b) Apply to this figure a unit price (per square or cubic meter), fixed by comparison to a "similar" building.

Unfortunately this method more often than not gives rise to inadequate sums insured. Indeed

- the total volume may be difficult to measure precisely

-it is next to impossible to define what a "similar" building is: most insurers leave the door open to subjectivity by using vague definitions like "luxury home", "middle-class house", or "working class house"

-the relative size of the non habitable parts (cellars, attics, garages, ...) may substantially affect the result

-the rebuilding cost usually depends on the region: so it is necessary to subdivide a country into more or less homogeneous areas, or to apply a correction factor depending on the area.

Clearly the evaluation of the rebuilding cost of a dwelling is a very intricate problem and it is not within anybody's possibilities to solve it precisely. Yet this is exactly what is being asked of every potential policyholder; the insurer, despite being one of the two contracting parties, does not bear any responsibility in the assessment: it is much easier to penalize under-insurance by applying the proportional rule! The insurers have nothing to be proud of in the light of this paradoxical situation: they are supposed to have the know-how, to be the fire insurance experts, and yet they leave the calculation of the most important element of the policy to the inexperienced policyholder.

\section{A FIRST EMPIRICAL MODEL}

In 1983, a leading Belgian insurer for the first time made a move towards the withdrawal of the under-insurance clause. It established a simple model to evaluate the value of a dwelling. The potential policyholder is invited to fill in a two-page form presented in Appendix I. The completion of the form, which takes roughly half an hour, provides an estimate of the rebuilding cost of the dwelling. If the client signs a policy with this evaluation as sum insured, the company forgoes the application of the proportional rule. Moreover, in the case of a large claim, the company accepts to pay the full rebuilding cost, even if it exceeds the estimate i.e., if the model was inaccurate. So the insurer accepts the possibility of paying more than the sum insured. This point is certainly worth mentioning since it seems the first time that the risk of a false evaluation is transferred to the insurer.

This first model was built empirically, after hours and hours of discussions between the company's non-life actuary, architects and assessors. Two major guidelines were constantly of paramount importance in this elaboration:

1. the method had to rely exclusively on objective, easy to check elements, such as areas, number, dimensions, presence or absence of a given material or 
equipment,.... Indeed, the insurer must have, after a claim, the opportunity to check the pieces of information mentioned in the form;

2. the method had to be simple enough, to be used by any individual policyholder. There would be no point in devising a highly efficient tool that would be so difficult to use that most policyholders would be discouraged.

Clearly simplicity of the evaluation procedure and precision of the result are two conflicting goals and many compromises had to be found. So a simple multiplication model rapidly emerged:

rebuilding cost $=$ factor representing the size of the dwelling

$\times$ factor representing the quality of the dwelling

$x$ index factor (official index of construction prices).

The very first model was based on the volume of the home; this immediately led to major difficulties:

(a) the total volume of a dwelling does not allow a distinction to be made between habitable rooms (bedrooms, living-room, kitchen, bathrooms, ...) and the non habitable rooms (cellars, garage,...);

(b) the height of the house (from the cellar's floor level to the mid-height of the roof) is in many cases difficult to measure accurately.

Those reasons led to the adoption as size factor of the product of the living-room's height by the total weighted floor area: the surface of each level is weighted according to its average rebuilding cost.

The overall quality of a building is at first sight a very subjective notion. The main idea of the method is to quantify this quality using a points system: around fifty representative criteria were selected and evaluated, establishing the presence or absence of certain material, equipment or architectural items.

So the final structure of the model is

$$
\begin{aligned}
\text { rebuilding cost }= & \text { weighted floor area } \times \text { height of living-room } \\
& \times \text { total number of points } \times \text { index factor } \\
& \times \text { normalizing coefficient. }
\end{aligned}
$$

This model was then tested and improved using a sample of thirty assessed dwellings.

Each difference between an assessed value and the corresponding predicted value was analysed. This often led either to a modification of the weight assigned to a type of room, or to a modification of a criterion: replacement by a more efficient criterion, adjustment of its quantitative importance or improved definition.

This process of empirical adjustments was stopped when it became clear that no significant improvement could be achieved, using the available data. The use of statistical techniques and of more reliable data became obvious. 


\section{THE STATISTICAL ANALYSIS}

At that stage the model was presented to the Professional Union of Insurance Companies. As at the same time the supervising Authorities of the Ministry of Economic Affairs expressed some concern about the proportional rule, the Union decided to finance a statistical study: 500 houses were to be assessed by two independent expert bureaus, and the sample was to be analysed by the Seminar of Actuarial Science of the Free University of Brussels. Clearly this sample size of 500 is extremely low (especially when one bears in mind that the model contains over 50 different parameters); this inevitably led to many statistical problems concerning the significance of the results. The reason why the sample size chosen was so small was of course the cost of data collection: it doesn't happen that often in insurance that the price of the collection of a single observation exceeds $\$ 15$ !

The houses to be assessed were not selected randomly: a stratification of all Belgian dwellings according to province, area type (urban or rural), construction year and number of outer walls was available from the National Institute of Statistics; the sampling technique was then devised in such a way as to respect the proportion of each cell. Within each cell, the assessors were given no special instruction as to the selection of the houses. To check for unintentional bias, a variable "reason for assessment" was introduced, taking the values

1. fire claim

2. water damage claim

3. storm claim

4. other claim

5. assessment.

Other variables, not present in the empirical model, were also recorded: these include the construction year, the postcode, the volume, the overall subjective quality (modest, comfortable, luxurious, left to the assessor's judgment), the unit price per $\mathrm{m}^{3}$ and the percentage of depreciation and wear and tear as evaluated by the assessor. Photographs of each house were taken, and proved to be very useful when checking for inaccuracies in the expert's reports.

Some exceptionally luxurious houses had to be eliminated: the main objective of the model is not to evaluate correctly the rebuilding cost of a 16th century castle with indoor swimming pool (see Appendix III). Some assessors' reports also had to be discarded because of obvious inaccuracies and contradictions. So the final sample size was reduced to 469 .

\section{Formulation of the Statistical Problem}

Let $x=\left(x_{1}, \ldots, x_{m}\right)$ a vector of $R^{m}$ characterizing a dwelling. The components of $x$ are all the elements of the model (floor areas, criteria) as well as other characteristics (construction year, geographical area,...). The rebuilding cost of the dwelling summarized by $x$ is a function $p\left(x_{1}, \ldots, x_{m}\right)$ of $R^{m} \rightarrow R$. Let $W(x)$ be the distribution function of $x$ within the Belgian housing stock. 
Let $\theta=\left(\theta_{1}, \ldots, \theta_{p}\right)$ denote the vector of unknown parameters of the model and $g(x, \theta)$ the evaluation of $p(x)$. As mentioned in Section 2, the following expression of $g(x, \theta)$ was selected.

$$
g(x, \theta)=\left(\sum_{t=1}^{49} x_{i} \theta_{i}\right) \cdot\left(\sum_{J=50}^{56} x_{j} \theta_{J}\right) \cdot x_{57} \cdot I \cdot L,
$$

where $x_{\imath}, i=1, \ldots, 49$, are dichotomic variables equal to zero or one depending on the answer to the criteria, $x_{j}, j=50, \ldots, 56$, are the total floor areas of the different types of rooms, $x_{57}$ is the height of the living-room, $I$ is the value of the official index of construction prices, $L$ is a normalizing coefficient, set at 0.125 so as to obtain manageable magnitudes for $\theta_{1}, \ldots, \theta_{49} . \theta_{53}$, the weight of the ground floor area, was set at 1 .

This specific form was chosen because of its simplicity and because the sample size is not sufficient to adjust more sophisticated models. Of course the model does not allow for possible interactions; it is likely that the quality of wall-to-wall carpet in a house with massive oak doors is superior to the quality of the carpet in a house with standard doors, but this effect will remain undetected.

$\theta$ could be determined in several ways. For instance

$$
\int_{|p(x)-g(x, \theta)|>k} d W(x)=\alpha
$$

the probability of an absolute error exceeding $k$ is equal to $\alpha$;

$$
\int_{|p(x)-g(x, \theta) / p(x)|>k} d W(x)=\alpha ;
$$

the probability of a relative error exceeding $k$ is equal to $\alpha$;

$$
\int_{g(x, \theta)<p(x)-k_{1}} d W(x)=\alpha_{1} \text { and } \int_{g(x, \theta)>p(x)+k_{2}} d W(x)=\alpha_{2} ;
$$

the respective probabilities of an under-esimation or an over-estimation exceeding $k_{1}$ and $k_{2}$ are equal to $\alpha_{1}$ and $\alpha_{2}$;

$$
\int[p(x)-g(x, \theta)]^{2} d W(x)=\min _{\zeta \in R^{p}} \int[p(x)-g(x, \zeta)]^{2} d W(x) .
$$

This least squares approach was selected, while the percentage of houses evaluated with a relative error exceeding $k$ was subsequently studied in the analysis of residuals. In the sequel, it is implicitly assumed that $g(x, \theta), p(x)$ and $W(x)$ satisfy all the regularity conditions such that $\theta$ is unequivocally determined.

\section{Estimation of $\theta$}

Assume $p(x)$ is a known function and denote $x^{1}, \ldots, x^{n}$ a simple random sample of dwellings. The least squares method amounts to determining the estimate $\hat{\theta}$ of $\theta$ by

$$
\sum_{j=1}^{n}\left[p\left(x^{J}\right)-g\left(x^{J}, \hat{\theta}\right)\right]^{2}=\min _{\zeta \in R^{p}} \sum_{J=1}^{n}\left[p\left(x^{J}\right)-g\left(x^{J}, \zeta\right)\right]^{2}
$$


Assuming $p(x), g(x, \theta)$ and $W(x)$ satisfy the assumptions of theorem 1 (Appendix IV), it can be shown that $\hat{\theta}$ almost surely converges to $\theta$; $\hat{\theta}$ is asymptotically normally distributed with mean zero and variance-covariance matrix $\Lambda^{-1} C\left(\Lambda^{t}\right)^{-1} / n$ where $\Lambda=E\left\{\partial_{\theta_{\theta} \theta_{j}}(p(x)-g(x, \theta))^{2}\right\}$ and $C$ is the variance-covariance matrix of $\left\{\partial_{\theta_{1}}(p(x)-g(x, \theta))^{2}, \ldots, \partial_{\theta_{p}}(p(x)-g(x, \theta))^{2}\right\}$.

In fact the form of $p(x)$ is unknown, since the rebuilding cost is evaluated by an expert. Denote by $e$ the assessment error. The sample is then $\left(x^{1}, p^{1}\right), \ldots,\left(x^{n}, p^{n}\right)$, where $p^{j}=p\left(x^{j}\right)+e^{j}, j=1, \ldots, n$. The estimation problem now becomes

$$
\sum_{j=1}^{n}\left[p^{J}-g\left(x^{J}, \hat{\theta}\right)\right]^{2}=\min _{\zeta \in R^{p}} \sum_{J=1}^{n}\left[p^{J}-g\left(x^{J}, \zeta\right)\right]^{2} .
$$

It can be shown (theorem 2, Appendix IV) that, if the assessment error has a zero mean and is independent of the characteristics of the dwelling, the estimation of $\theta$ is unbiased but less efficient (more observations are necessary to obtain the same level of accuracy if there are assessment errors).

\section{Main Results}

The sample size is evidently too low to accurately estimate all the parameters; anomalies between some parameter values were bound to appear, among other reasons because several characteristics were hardly represented in the sample (there was no house with heat pumps in the sample, for instance). Therefore, after many trial and error runs, it was decided to adopt the following procedure:

Step 1: Estimation of all the parameters, excluding the weight of the nonhabitable annexes.

Step 2: Detection of inconsistencies; modification (following the experts' advice) of the number of points assigned to those anomalous criteria.

Step 3: Those points being fixed, estimation of all the other parameters, excluding the weight of the non-habitable annexes.

Step 4: Estimation of the weight of the non-habitable annexes.

The main modifications that occurred in the analysis are briefly described in the sequel.

-A detailed statistical analysis of the residuals led to a slightly different determination of the parameters: let $V(x)$ be the dwelling volume, and $U(x)$ the rebuilding cost per $\mathrm{m}^{3} . \theta$ is then defined by

$$
\int\left[U(x)-\frac{g(x, \theta)}{V(x)}\right]^{2} d W(x)=\min _{\zeta \in R^{p}} \int\left[U(x)-\frac{g(x, \zeta)}{V(x)}\right]^{2} d W(x) .
$$

In other words, the price per $\mathrm{m}^{3}$ of the model is adjusted to the price per $\mathrm{m}^{3}$ provided by the assessor (the first formulation led to unacceptably large relative errors for the large dwellings).

- The height of the living-room was limited to 3.5 metres.

-The difference in number of outer walls is not reflected in the basic points any more, but in differentiated normalizing coefficients. 
-The number of points assigned to each criteria was modified, in some cases substantially.

- Some supplementary variables were introduced, others were discarded or modified.

The final version of the model is given in Appendix II.

\section{The Quality of the Model}

Figure 1 shows that the overall predictive power of the model is excellent. The correlation coefficient between the predicted value and the assessor's value is 0.9673 .

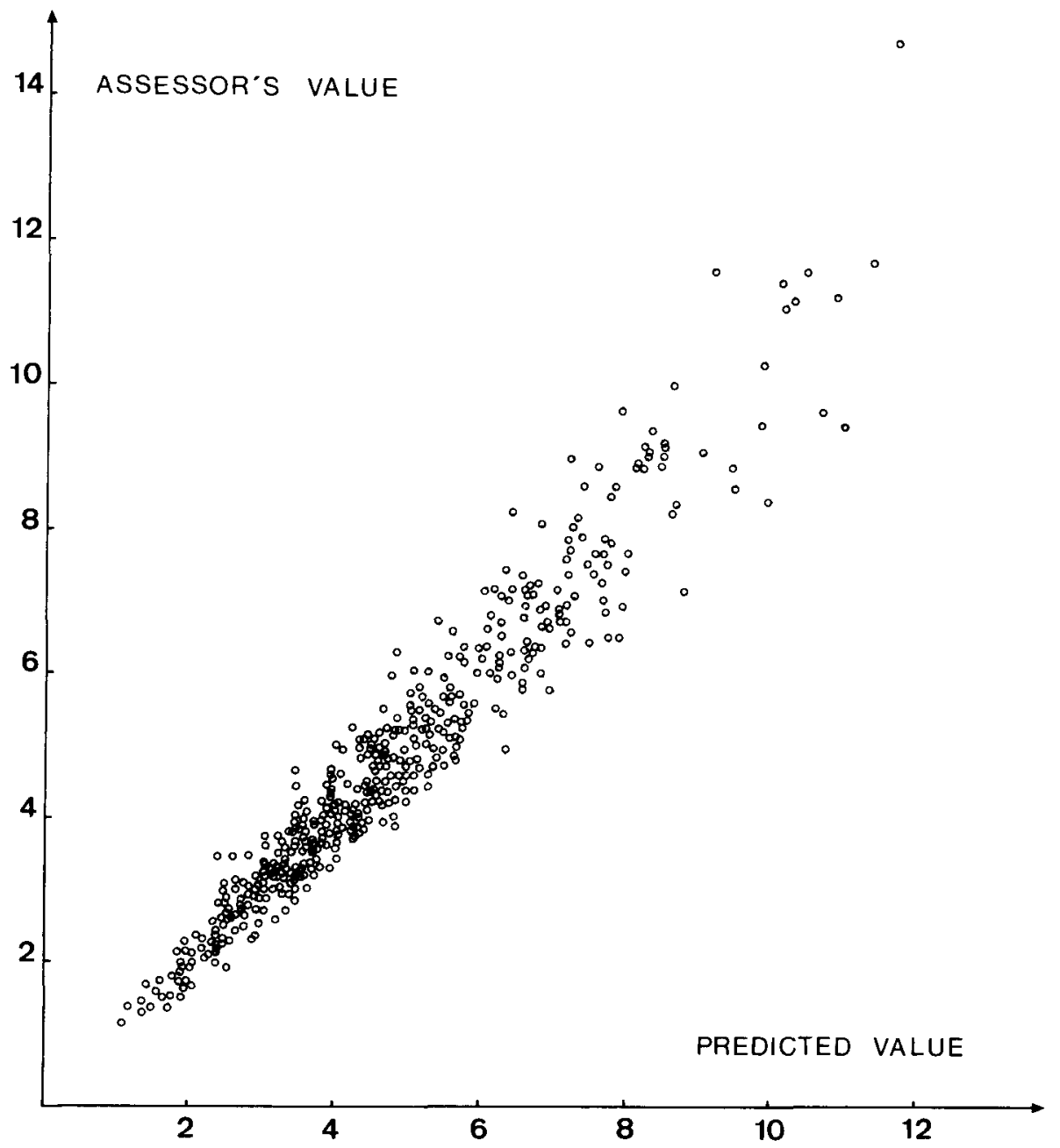

FIGURE 1. (In Million Belgian Francs). 


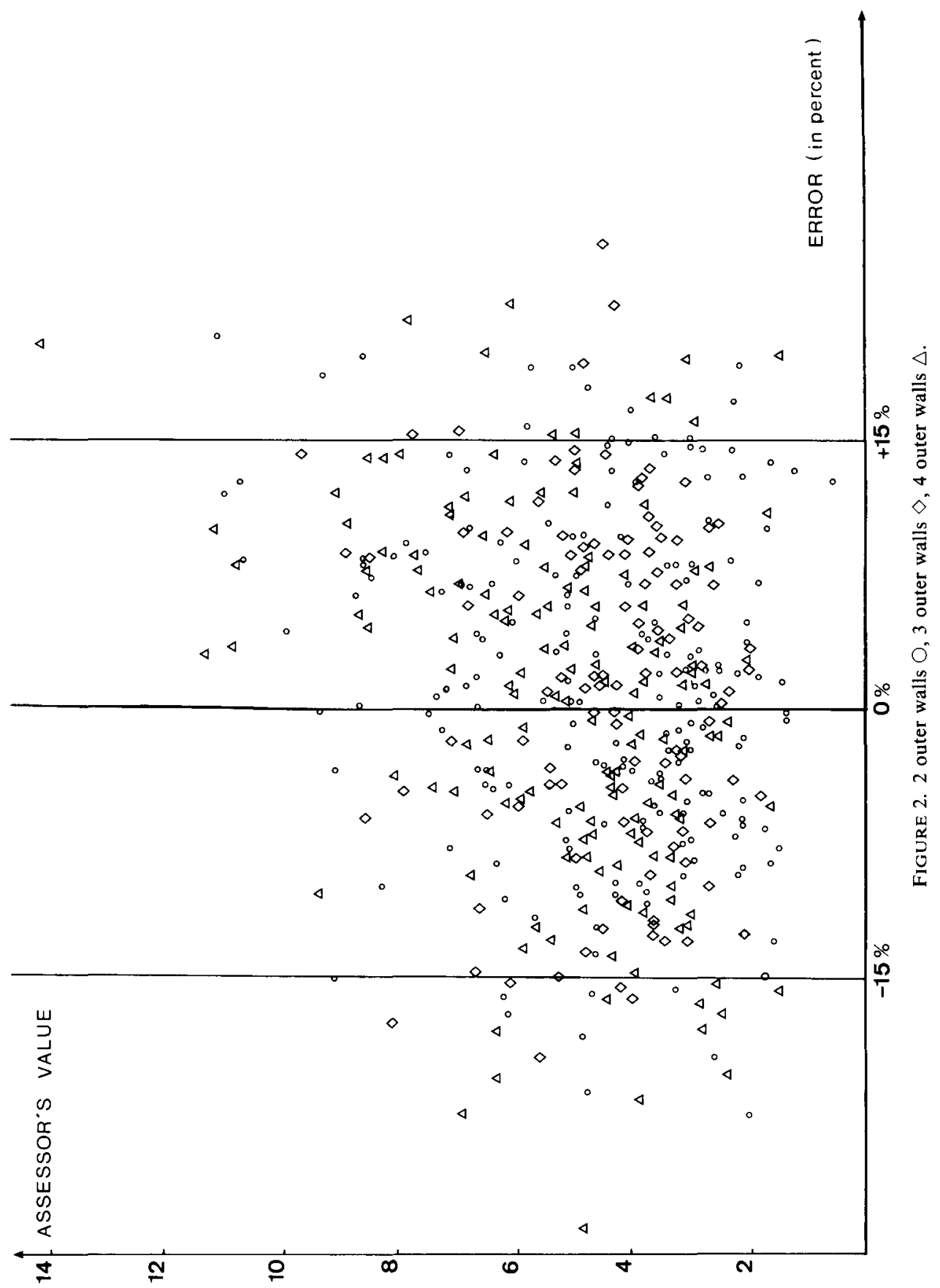


Figure 2 shows that the distribution of the residuals does not depend on the value of the house or the number of outer walls. So systematic bias seem to have been eliminated. Nevertheless, 56 houses $(12 \%)$ are estimated with a relative error exceeding $15 \%$; the largest relative error amounts to $29 \%$.

Evidently the low sample size accounts for very large confidence intervals for all parameters.

The average price per $\mathrm{m}^{3}$ is 7121.53 Frs. The standard deviation of the residuals amounts to $694.27 \mathrm{Frs}$; the average is 44.75 Frs (different from zero, since the model is non linear) and the semi-interquartile range equals $463.33 \mathrm{Frs}$; so one house out of two is over- or under-evaluated by more than 463.33 Frs per $\mathrm{m}^{3}$ (or $6.5 \%$ ).

Any evaluation of the overall performance of the model must of course take into consideration the fact that the assessors are also subject to error. The experts admit they may be wrong by more than $10 \%$ in $10 \%$ of the cases. In the absence of any other information related to the quality of the assessors' evaluations, and assuming normality, this leads to a standard deviation of 432.92 Frs and a semi-interquartile range of 291.78 Frs. So the model's performance rates nearly as good as the assessors'.

\begin{tabular}{lcc}
\hline \hline & Model & Experts \\
\hline Standard deviation & 69427 & 43292 \\
Semi-1nterquartile range & 46333 & 29178 \\
\hline
\end{tabular}

Analysis of Other Variables

An analysis of variance (classical six-way layout, without interaction) of the residuals as a function of the variables not selected in the model led to the following results.

\begin{tabular}{lccc}
\hline \hline \multicolumn{1}{c}{ Sources of Variation } & $\begin{array}{c}\text { Degrees of } \\
\text { Freedom }\end{array}$ & $\begin{array}{c}\text { Sums of } \\
\text { Squares }\end{array}$ & $F$ \\
\hline $\begin{array}{l}\text { Region } \\
\quad \text { Brussels, Flanders, Wallony) }\end{array}$ & 2 & 2197383 & 236 \\
$\begin{array}{l}\text { Area type } \\
\quad \text { (urban, rural) }\end{array}$ & 1 & 182885 & 039 \\
Province & 9 & 9361193 & 223 \\
Construction year & 3 & 1017155 & 073 \\
Overall quality & 3 & 2284022 & 164 \\
Reason for assessment & 5 & 3383362 & 145 \\
Error & 445 & 207157512 & \\
\hline Total & 468 & 225583512 & \\
\hline
\end{tabular}

Among the positive results, the area type, the construction year, the overall quality and the reason of assessment do not significantly influence $(\alpha=10 \%)$ the estimate provided by the model.

To account for the predictable influence of the province and the region, a further adjustment was performed, introducing an additional multiplying coefficient (see following table). 


\begin{tabular}{ll}
\hline \hline \multicolumn{1}{c}{ Province } & Coefficient \\
\hline Brabant & 1.00 (set) \\
West Flanders & 0.98 \\
East Flanders & 1.00 \\
Antwerp & 0.98 \\
Limburg & 0.96 \\
Liège & 0.99 \\
Hainaut & 0.97 \\
Namur & 1.06 \\
Luxemburg & 1.04 \\
\hline
\end{tabular}

Belgium being a fairly homogeneous country, the differences are rather small; some of those coefficients were nevertheless qualified as unrealistic by the experts. Considering the practical difficulties that these criteria would give rise to (for instance in the case of dwellings situated near a province border), it was decided not to introduce it in the model.

\section{Percentage of Depreciation and Wear and Tear}

Remember that this figure has to be used by the tenant of a dwelling to correctly determine the sum insured. The evaluation of that percentage by the experts led to the following averages.

\begin{tabular}{lc}
\hline \hline Construction Year & $\begin{array}{c}\text { Percentage of } \\
\text { Depreciation }\end{array}$ \\
\hline Before 1920 & $17.7 \%$ \\
$1920-1945$ & $15.3 \%$ \\
$1945-1970$ & $11.1 \%$ \\
After 1970 & $4.6 \%$ \\
\hline Total & $12.2 \%$ \\
\hline
\end{tabular}

Given the uncertainties of the evaluations, it was decided, for the sake of administrative simplicity, to use in the model the global average of $12.2 \%$ for all dwellings.

\section{CONCLUSIONS}

As mentioned earlier, the selected model is the result of many compromises between simplicity and accuracy. Admittedly, it is not perfect; the selection, definition and evaluation of the criteria, the accuracy of the weights, ... could be improved if more data were available. Nevertheless it seems to us that a widespread use of the model is bound to improve the position of all parties concerned in homeowner insurance.

* The policyholder, finally safe from under-insurance, would have the assurance of being fully compensated, in the event of a claim; he would no longer risk seeing a lifetime of savings disappear in a few hours. 
* The insurance broker or agent would enhance his role as an efficient and conscientious adviser; the systematic use of the model would give greater stability to his portfolio, as clients often switch over to competitors who exploit under-insurance to attract new business.

* The insurer would improve his reputation by sharing with his policyholder the responsibility for the determination of the sum insured and by ceasing to apply the infamous proportional rule. His expenses would be ridden of the cost of many post-claim assessments, since it would only be necessary to check the truthfulness of the information provided by the policyholder upon completion of his form.

In the long run, a generalized use of the model would lead to a more equitable allocation of the cost of small claims (to which the proportional rule is not applied whether there is under-insurance or not) and hence to a decrease of premium rates.

\section{APPENDIX I}

THE FIRST EMPIRICAL MODEL

The policyholder has to fill in two pages; on the first, he has to compute the floor area of each room, multiply it by a coefficient, and add the various results. Note that different weights are used for houses and flats. In the second page, he has

Computation of the total Weighted floor area

\begin{tabular}{|c|c|c|c|}
\hline Levels & Surface & Weight & $\begin{array}{l}\text { Weighted } \\
\text { Surface }\end{array}$ \\
\hline \multicolumn{4}{|l|}{ House } \\
\hline $\begin{array}{l}\text { Basement (not transformed into habitable rooms, situated } \\
\text { partially or totally below ground level) }\end{array}$ & & 0.75 & \\
\hline $\begin{array}{l}\text { Ground floor (including annexes transformed into habitable } \\
\text { rooms) }\end{array}$ & & 1 & \\
\hline Upper floors and attic (if transformed into habitable rooms) & & 1 & \\
\hline $\begin{array}{l}\text { Attic (ignore if not accessible or if height less than } 1.5 \\
\text { metres) }\end{array}$ & & 0.60 & \\
\hline $\begin{array}{l}\text { Non habitable annexes (garage, store-rooms, garden-sheds, } \\
\text { green houses, covered terraces, workshops, ...) }\end{array}$ & & 0.75 & \\
\hline Total weighted surface & & & $\mathrm{m}^{2}$ \\
\hline \multicolumn{4}{|l|}{ Flat } \\
\hline Main apartment & & 1 & \\
\hline $\begin{array}{l}\text { Other private premises (garage, cellars, attics, annexes, } \\
\text { parking places, basement, ...) }\end{array}$ & & 0.75 & \\
\hline \multicolumn{4}{|l|}{$\begin{array}{l}\text { The common parts of the building (lift, stairs, entrance, } \\
\text { hall, ...) must not be taken into consideration }\end{array}$} \\
\hline Total weighted surface & & & $\mathrm{m}^{2}$ \\
\hline
\end{tabular}


to record the presence or absence of various items and add the points assigned to each criterion. The rebuilding cost is then obtained by performing simple multiplications. Note that in this English presentation we deliberately adopted a simplified terminology: the original French version of the form uses very elaborate definitions of the criteria; our main aim in this translation is to allow all non-native speakers of English to understand this text without a dictionary of architectural terms.

\begin{tabular}{lcc}
\hline \hline Criteria & Points \\
\hline
\end{tabular}

1. Fabric

Street frontage

Painted bricks, concrete

Other material (even if partially)

Decorative free stones

Balcony or terrace with hand-rail

Attic window(s) in the roof

Roof in natural slates, flat tiles or thatched

0

2

2

3

2

2. External woodwork

Window frames and outer doors

* In natural aluminium

* In exotic wond or oak, in tinted aluminium or in plastic (even if partially) Leaded glass windows (even if partially)

Shutters (even if partially)

3. Internal woodwork

Living-room doors

* Standard doors, painted or veneered wood 0

* Other doors, even if partially (solid wood, profiled, glazed, glass door,...) 5

Built in wall cupboards

Built in kitchen furniture

Without embedded appliance

With embedded appliance(s)

4. Heating

* Gas radiators

* Central heating: gas, electricity (direct or by accumulation)

* Central heating: fuel

* Central heating: coal

* Central heating: heat pumps

5. Insulation

Insulation of outer walls

Insulation of roof

Double, triple glazing or double window frames, everywhere

Double, triple glazing or double window frames, partially

6. Sanitary facilities

Per bathroom with bath

Per bathroom with shower

Coloured sanitary appliance(s) (even if partially)

Built in bathroom furniture

7. Electrical installation

Designed for electric cooker or oven

Designed for electric washer and/or drier

Checked (even partially) by electricity company after January 1, 1970 


\begin{tabular}{|c|c|}
\hline Criteria & Points \\
\hline \multicolumn{2}{|l|}{ 8. Covering, decoration } \\
\hline Mural tiles in bathroom or shower & 3 \\
\hline \multicolumn{2}{|l|}{ Living-room walls } \\
\hline * Painted & 0 \\
\hline * Papered, rough-cast & 2 \\
\hline * Other material (wood, cork,...) even if partially & 6 \\
\hline \multicolumn{2}{|l|}{ Living-room floor } \\
\hline * Wall-to-wall carpet, tiled flooring & 4 \\
\hline * Natural stones, wooden floor & 6 \\
\hline \multicolumn{2}{|l|}{ Living-room ceiling } \\
\hline * Painted or papered ceiling without moulding & 0 \\
\hline * Moulded, panelled or false ceiling & 5 \\
\hline $\begin{array}{l}\text { Stair in exotic wood or oak (varnished or tinted), stair covered with marble or } \\
\text { decorative stone }\end{array}$ & 4 \\
\hline Decorative fireplace in marble or stones, open fireplace & 4 \\
\hline \multicolumn{2}{|l|}{ 9. Basic points } \\
\hline \multicolumn{2}{|l|}{ Houses } \\
\hline Terraced ( $=2$-outer walls house) & 110 \\
\hline Semi-detached ( $=3$-outer walls house) & 126 \\
\hline Detached (=4-outer walls house) & 132 \\
\hline Flat roof & 20 \\
\hline Main building totally on underfloor void area & 10 \\
\hline Main building partially on underfloor void area & 5 \\
\hline \multicolumn{2}{|l|}{ Apartments } \\
\hline Without lift & 160 \\
\hline With lift & 170 \\
\hline
\end{tabular}

Total number of points

(*) If affirmative response to several of the alternatives marked with an asterisk, select the highest number of points.

Computation of Rebuilding Cost

\begin{tabular}{|c|c|c|c|c|c|}
\hline $\begin{array}{l}\text { Total } \\
\text { Number } \\
\text { of } \\
\text { Points }\end{array}$ & $\begin{array}{c}\text { Latest } \\
\text { Construction } \\
\text { Index } \\
\text { Value }\end{array}$ & Coefficient & $\begin{array}{l}\text { Height of } \\
\text { Living-room }\end{array}$ & $\begin{array}{c}\text { Total } \\
\text { Weighted } \\
\text { Floor } \\
\text { Area }\end{array}$ & $\begin{array}{c}\text { Rebuilding } \\
\text { Cost }\end{array}$ \\
\hline & $x$ & $\times 0.125$ & $x$ & $x$ & $=$ \\
\hline
\end{tabular}

The average value of a point roughly equals 25000 Belgian Francs. Note that the quotation of some criteria, like the coloured sanitary appliances or the wooden walls, has been deliberately overstated. These criteria, indicative of luxurious decoration or equipment, have been overrated in order to indirectly take into account some other non-selected criteria. For example, the presence of mural mosaic tiles in a bathroom or cork-covered walls in a living-room is an indicator of overall luxury decoration in the house. 


\section{APPENDIX II}

THE FINAL MODEL

The recommended model has the following form

\begin{tabular}{|c|c|c|c|c|c|}
\hline $\begin{array}{c}\text { Total } \\
\text { Number } \\
\text { of } \\
\text { Points }\end{array}$ & $\begin{array}{c}\text { Latest } \\
\text { Construction } \\
\text { Index } \\
\text { Value }\end{array}$ & Coefficient & $\begin{array}{l}\text { Height of } \\
\text { Living-room }\end{array}$ & $\begin{array}{c}\text { Total } \\
\text { Weighted } \\
\text { Floor } \\
\text { Area }\end{array}$ & $\begin{array}{c}\text { Rebuilding } \\
\text { Cost }\end{array}$ \\
\hline & $x$ & $x$ & $x$ & $x$ & $=$ \\
\hline
\end{tabular}

where the height of the living-room (in metres) is limited to $3.5 \mathrm{~m}$; the normalizing coefficient equals 0.116 for a terraced ( 2 outer walls) house or a semi-detached ( 3 outer walls) house with a blind wall (maximum one opening of $2 \mathrm{~m}^{2}$ ) and 0.125 for all other dwellings; the total weighted floor area (in $\mathrm{m}^{2}$ ) equals $\sum_{j=50}^{56} \theta_{J} x_{j}$ where

$x_{50}=$ area of attic (not transformed into habitable rooms.

Ignore if not accessible or if height less than 1.5 metre) $\theta_{50}=0.50$

$x_{51}=$ area of attic (converted into habitable room)

$\theta_{51}=0.75$

$x_{52}=$ upper floor(s) area

$\theta_{52}=0.90$

$x_{53}=$ ground floor area

$\theta_{53}=1$

$x_{54}=$ area of habitable basement

$\theta_{54}=0.60$

$x_{55}=$ area of non-habitable basement

$\theta_{55}=0.55$

$x_{56}=$ area of non-habitable annexes

$\theta_{56}=0.35$

The points are defined in the following table:

Criteria $P$ Points

1. Fabric

Street facade with ornamental bricks or quarry-stones

Natural decorative stones or free stones

Balcony or terrace

Attic window

Flat roof on main building

Single storey house

Multi storey house

3

3

3

6

25

15

Roof with mild slope or inaccessible attic on main building (only if no attic area is introduced in the computation of the total weighted floor area)

Single storey house

Multi storey house

Roof in flat tiles or thatched

Roof in natural slates

Blind wall (maximum one opening of $2 \mathrm{~m}^{2}$ )

One wall

Two walls

Dwelling partially used for commercial purposes with show-windows

Front garden wall (masonry, stone, concrete, wood or plants)

2. External woodwork

Window-frames and outer doors in exotic wood, oak, tinted aluminium, even if partially 


\begin{tabular}{cc}
\hline Criteria & Points \\
\hline
\end{tabular}

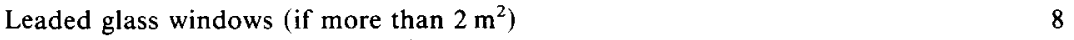

Roll-up shutters (even if partially)

Vertical hinged shutters (even for decorative purposes, even if partially) 9

3. Internal woodwork

Living-room doors

* Standard doors, painted or veneered wood 0

* Other doors (solid wood, exotic or oak, varnished or tinted, glass door,..., even if partially)

Built-in wall cupboards, used as wardrobes or linen closets

* One cupboard

* Several cupboards

Built in kitchen furniture

* Without embedded appliance $\quad 3$

* With embedded appliance(s) 6

4. Heating

* Gas radiators

* Central heating: gas, fuel, coal, electricity (direct or by accumulation) 13

$\begin{array}{ll}* \text { Central heating: heat pumps } & 18\end{array}$

5. Insulation

Insulation of outer walls 3

Insulation of roof or of attic floor 3

Double, triple glazing or double window frames, everywhere 6

Double, triple glazing or double window frames, partially 4

6. Sanitary facilities

* Bathroom with bath 7

* Bathroom with shower 5

More than one bathroom for every two bedrooms $\quad 22$

Coloured sanitary appliance(s) (even if partially) 5

Built in bathroom furniture 3

7. Electrical installation

Designed for one appliance, such as electric cooker, oven, dishwasher or washing machine and/or checked (even if partially) by electricity company after January 1,1970

Designed for several appliances and/or checked (even in partially) by electricity company after January 1, 1981

8. Coverings, decoration

Mural mosaic tiles in bathroom or shower 7

Mural tiles in kitchen (if more than $2 \mathrm{~m}^{2}$ ) 4

Living-room walls

* Painted, papered, rough cast

* Other (woven materials, wood, cork, stone, decorative bricks, even if partially) 8

Living-room floor

* Wall-to-wall synthetic carpet, tiled flooring

* Wall-to-wall wool carpet, natural stones, wooden floor

Living-room ceiling

* Painted or papered ceiling without mouldings $\quad 0$

* Moulded, panelled or false ceiling $\quad 6$

Decorative or open fireplace $\quad 3$

$\begin{array}{ll}\text { 9. Basic points } & 137\end{array}$

* If affirmative response to several of the alternatives mariked with an asterisk, select the highest number of points. 
The discrepancies between the empirical, "logical" model and the statistical model are worth noticing. In the empirical construction, the number of points assigned to each criterion was determined in such a way that the increase in the rebuilding value matches the price of the equipment. For instance the average cost of a bathroom amounts to $100000 \mathrm{Frs}$, and the extra cost of building a roof in natural slate or a thatched roof equals 125000 Frs. Since the average value of a point equals $25000 \mathrm{Frs}$, it was considered logical to assign the respective values of 4 and 5 points to those criteria. The non linear least squares statistical approach, on the other hand, did not consider the price value of the various items, but clearly focussed on the degree of luxury involved with each criterion. In Belgium, only luxury houses have a roof in natural slate, and exceptionally luxurious homes have a thatched roof; so the statistical analysis assigned respectively 15 and 20 points to those criteria, far above the building price of such roofs. Also the statistical analysis detected that the luxury element in the sanitary facilities is not the number of bathrooms, but the ratio of bathrooms per bedrooms; it assigned a number of points (22) out of proportion of the cost to a dwelling for which this ratio exceeds one half. Other examples of criteria whose quotation rose, not because of the price of the item but because they are indicative of overall luxury, include vertical hinged shutters (nine points instead of three) and coloured sanitary facilities (five points instead of two). In a few cases the value of a criterion decreased; for instance the number of points assigned to synthetic wall-to-wall carpet or tiles in the living-room dropped from four to zero; these materials are of course not free of charge, but are very common nowadays: their presence or absence is not significant.

\section{APPENDIX III \\ LIMITS OF APPLICATION}

The model was designed to estimate correctly the value of "ordinary" dwellings. In the case of exceptionally large or luxurious homes, its results are sometimes misleading After analysis of the residuals and consultation of the assessors,

\begin{tabular}{lc}
\hline \multicolumn{1}{c}{ Criteria } & Points \\
\hline 1 Basis for property taxation (defined as $60 \%$ of the normal annual rent) in excess & 10 \\
of 200000 francs & 10 \\
2 Indoor swimming pool & 10 \\
3 Lift in single family house & 10 \\
4 More than one outer wall entirely in natural stone & 10 \\
5 Total floor area (non habitable annexes excluded) exceeding of $450 \mathrm{~m}^{2}$ & 5 \\
6 Solar heating and/or heat pumps & 5 \\
7 More than one bathroom for every two bedrooms & 5 \\
8 Roof with flat tıles or thatched & 5 \\
9 Garage for more than two cars & 4 \\
10 Living room floor-covering in natural stones & 4 \\
11 Textıle wall-covering, even if partially & 4 \\
12 More than $50 \%$ of total outer wall area glazed & \\
\hline
\end{tabular}


another points system was devised to check whether a dwelling can be evaluated by the model or not; twelve criteria were selected; if the total number of points reaches or exceeds 10 , the method is not to be applied.

\section{APPENDIX IV}

THEOREM 1. Let $\partial_{\theta}[p(x)-g(x, \theta)]^{2}=\psi(x, \theta)$. If $\forall \theta, \psi(x, \theta)$ is measurable and separable, if $\exists \theta_{0}$ such that $\mathbb{E}\left[\psi\left(x, \theta_{0}\right)\right]=0$, if $\exists a, b, c, d_{0}>0$ such that

where

$$
\begin{array}{cc}
|\mathbb{E}[\psi(x, \theta)]| \geqslant a\left|\theta-\theta_{0}\right| & \text { for }\left|\theta-\theta_{0}\right| \leqslant d_{0}, \\
\mathbb{E}[u(x, \theta, d)] \leqslant b d & \text { for }\left|\theta-\theta_{0}\right|+d \leqslant d_{0}, \\
\mathbb{E}\left[u^{2}(x, \theta, d)\right] \leqslant c d & \text { for }\left|\theta-\theta_{0}\right|+d \leqslant d_{0},
\end{array}
$$

$$
u(x, \theta, d)=\sup _{|\xi-\theta| \leqslant d}|\psi(x, \xi)-\psi(x, \theta)|,
$$

and if $\mathbb{E}[\psi(x, \theta)]$ has a non singular derivative matrix $\Lambda$, then $\hat{\theta}$, satisfying

$$
\frac{1}{\sqrt{n}} \sum_{j=1}^{n} \psi\left(x^{j}, \hat{\theta}\right)=0
$$

is asymptotically normally distributed, with mean zero and variance-covariance matrix $\Lambda^{-1} C\left(\Lambda^{t}\right)^{-1}$, where $C$ is the variance-covariance matrix of $\psi\left(x, \theta_{0}\right)$. (Source: Huber, P. J. (1981) Robust Statistics. Wiley)

TheOREM 2. Let $\hat{\theta}$ be defined by

$$
\int[p(x)+e-g(x, \hat{\theta})]^{2} d W(x) d E=\min _{\theta \in R^{p}} \int[p(x)+e-g(x, \theta)]^{2} d W(x) d E,
$$

where $E(x)=\mathbb{P}(e \leqslant x), \mathbb{E}(e)=0$ and $\mathbb{E}\left(e^{2}\right)=\sigma^{2} . \hat{\theta}$ is the vector of parameters with assessment errors. Then

1. $\hat{\theta}=\theta$, where $\theta$ is the vector of parameters without assessment errors.

2. The variance-covariance matrix of $\hat{\theta}$ is $\Lambda^{-1} C\left(\Lambda^{t}\right)^{-1}+4 \sigma^{2} \Lambda^{-1} A\left(\Lambda^{t}\right)^{-1}$, where $A$ is the variance-covariance matrix of $\partial_{\theta}[p(x)-g(x, \theta)]$.

Proof.

$$
\text { 1. } \begin{aligned}
& \partial_{\theta} \int {[p(x)+e-g(x, \theta)]^{2} d W(x) d E } \\
&=\partial_{\theta} \int\left\{[p(x)-g(x, \theta)]^{2}-2[p(x)-g(x, \theta)] e+e^{2}\right\} d W(x) d E \\
&=\partial_{\theta} \int[p(x)-g(x, \theta)]^{2} d W(x) .
\end{aligned}
$$

2. Apply theorem 1 with $\hat{\psi}(x, \theta)=\partial_{\theta}[p(x)+e-g(x, \theta)]^{2}$.

Freddy Corlier, Jean-François Ingenbleek and Jean Lemaire Institut de Statistiques, C.P. 210, 50 Boulevard du Triomphe, B-1050 Bruxelles. 